\title{
Fungal Pathogens: Survival and Replication within Macrophages
}

\author{
Andrew S. Gilbert ${ }^{1}$, Robert T. Wheeler ${ }^{2,3}$, and Robin C. May ${ }^{1,4}$ \\ ${ }^{1}$ Institute of Microbiology and Infection \& School of Biosciences, University of Birmingham, Edgbaston, \\ Birmingham B15 2TT, United Kingdom \\ ${ }^{2}$ Department of Molecular and Biomedical Sciences, University of Maine, Orono, Maine 04469 \\ ${ }^{3}$ Graduate School of Biomedical Sciences and Engineering, University Hospitals of Birmingham NHS \\ Foundation Trust, Queen Elizabeth Hospital, Birmingham B15 2TG, United Kingdom \\ ${ }^{4}$ NIHR Surgical Reconstruction and Microbiology Research Centre, University Hospitals of Birmingham \\ NHS Foundation Trust, Queen Elizabeth Hospital, Birmingham B15 2TG, United Kingdom \\ Correspondence: r.c.may@bham.ac.uk
}

\begin{abstract}
The innate immune system is a critical line of defense against pathogenic fungi. Macrophages act at an early stage of infection, detecting and phagocytizing infectious propagules. To avoid killing at this stage, fungal pathogens use diverse strategies ranging from evasion of uptake to intracellular parasitism. This article will discuss five of the most important human fungal pathogens (Candida albicans, Aspergillus fumigatus, Cryptococcus neoformans, Coccidiodes immitis, and Histoplasma capsulatum) and consider the strategies and virulence factors adopted by each to survive and replicate within macrophages.
\end{abstract}

\begin{abstract}
M acrophages are phagocytic immune cells, derived from monocyte differentiation, and are involved in the first line of defense during microbial invasion. They recognize, engulf, and destroy foreign bodies, such as pathogenic organisms before then presenting antigen to coordinate subsequent adaptive immunity (Fig. 1). Macrophages are found in almost all tissues and are particularly abundant at mucosal surfaces in which pathogen exposure is naturally higher, such as the alveoli. They are able to engulf particles ranging from $0.5 \mu \mathrm{m}$ (such as bacteria) to $>5 \mu \mathrm{m}$ (such as yeast), although an upper size limit does exist (Chen et al. 1997; Krombach et al. 1997; Kinchen and Ravichandran 2008).
\end{abstract}

Macrophages express a wide range of different receptors able to detect nonself particles. These receptors can be split into two groups: opsonic and nonopsonic. Opsonic receptors, such as the Fc receptor or complement receptor families (Flannagan et al. 2012), are able to recognize particles coated (opsonized) in antibody or complement (Johnston and May 2013). In contrast, nonopsonic receptors are pathogen recognition receptors (PRRs) that directly detect pathogen-associated molecular patterns (PAMPs) on the surface of microorganisms. Macrophages are heterogeneous in the receptors they express, and can change this repertoire when differentiating into different subtypes. For instance, the nonopsonic Dectin-1 receptor

Editors: Arturo Casadevall, Aaron P. Mitchell, Judith Berman, Kyung J. Kwon-Chung, John R. Perfect, and Joseph Heitman Additional Perspectives on Human Fungal Pathogens available at www.perspectivesinmedicine.org

Copyright (C) 2015 Cold Spring Harbor Laboratory Press; all rights reserved; doi: 10.1101/cshperspect.a019661 Cite this article as Cold Spring Harb Perspect Med 2015;5:a019661 
A.S. Gilbert et al.

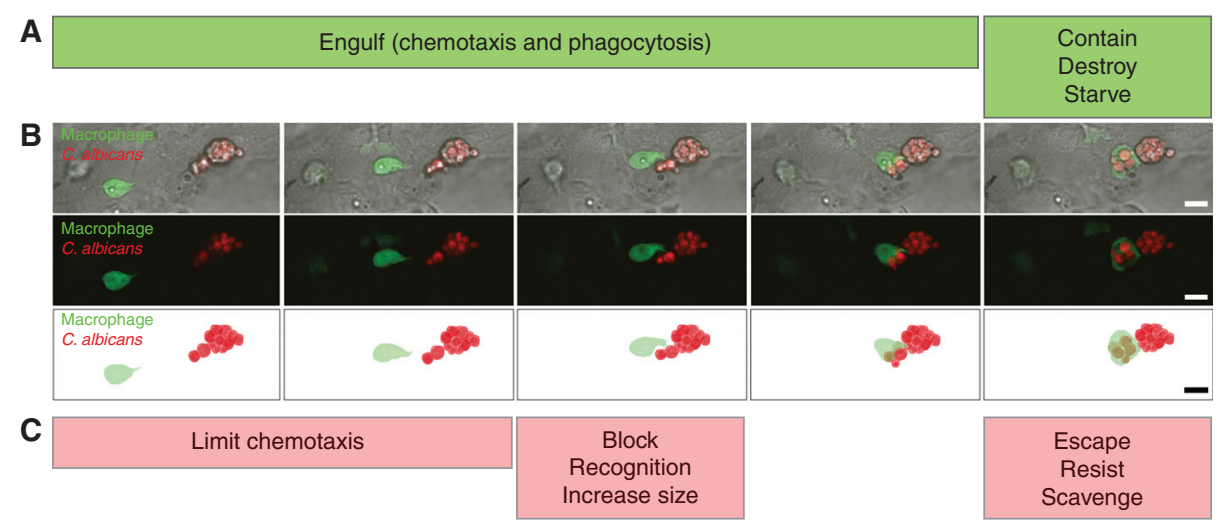

Figure 1. Fungal defenses against phagocytic attack. (A) For phagocytes to destroy fungal pathogens, they must first arrive at the site of infection and move into contact with fungi by long-range and short-range chemotaxis. Once a macrophage contacts a fungal cell via opsonic and/or nonopsonic receptors, it can initiate phagocytosis. Engulfed fungal cells are then trafficked to the phagolysosome where they are subjected to hydrolases, noxious reactive oxygen, and nitrogen species, and starvation from easily metabolized carbon, nitrogen, and trace nutrients. (B) Schematic of phagocytosis time lapse taken by intravital imaging in the zebrafish. Macrophages express green fluorescent protein and C. albicans yeast express mCherry fluorescent protein. Frames are from 1-, 3-, 4-, 5-, and 6-min time points (left to right) during this interaction. Scale bars, $10 \mu \mathrm{m}$. (C) Pathogenic fungi have evolved mechanisms to limit chemotaxis, block recognition, inhibit phagocytosis, escape phagolysosomes, resist microbicidal attack, and scavenge nutrients within the macrophage.

serves as a marker of M2-type macrophages (Biswas and Mantovani 2010; Gordon and Martinez 2010). This provides for multiple paths to engulfment and different responses depending on macrophage subtype and activation state.

Once engulfment has been achieved, the macrophage must then digest the pathogen, now segregated into a phagosome (digesting vesicle). To complete the digestion, the phagosome must mature via the fusion of early and late stage endosomes and ultimately fuse with the lysosome, generating a phagolysosome (Kinchen and Ravichandran 2008). The phagolysosome uses vacuolar ATPases to pump $\mathrm{H}^{+}$ions into the phagolysosome, reducing the $\mathrm{pH}$. Once the $\mathrm{pH}$ is reduced sufficiently, acid-dependent proteases, such as cathepsin D, are activated to degrade the pathogen (Fig. 1) (Kinchen and Ravichandran 2008).

Many human fungal pathogens have developed strategies to resist phagocytic attack, thus facilitating pathogenicity. The field of fungal research has exploded over the last three decades because of the increase in fungal-related illnesses that appears to correlate with the AIDS pandem- ic and more effective immunosuppressive medicines (Brown et al. 2012). Macrophages have been shown to play a role in resistance to disseminated candidiasis, although they are believed to play a supporting role relative to the neutrophil. (Calderone and Sturtevant 1994; Vázquez-Torres and Balish 1997; Lionakis et al. 2013). Rigorous testing of the role of macrophages in fungal disease in the human and mouse has lagged behind examination of the neutrophil's role in immunity, as specific ablation of neutrophils is possible experimentally and seen clinically in several patient populations. Here we discuss how many clinically important fungal pathogens resist macrophage attack.

\section{Candida SPECIES}

Candida albicans, Candida glabrata, Candida tropicalis, and Candida parapsilosis are well adapted, commensal ascomycetes considered part of the natural microflora associated with warm mucosal regions, such as the gut, mouth, and vagina (Miramón et al. 2013). It has been estimated that $75 \%$ of the population harbors a 
population of Candida species within their oral mucosa (Scully et al. 1994; Mayer et al. 2013). C. albicans, C. glabrata, C. parapsilosis, Candida krusei, and C. tropicalis all have the genetic machinery to cause both superficial mucosal infections, commonly known as thrush, and life-threatening systemic candidiasis. The predisposition to initiate invasive infection is predominantly some form of immunosuppression either through disease, such as HIV/AIDS or diabetes, or being placed on immunosuppressive therapies, for example, after organ transplant surgery (Miramón et al. 2013). Candida infections often arise in patients fitted with a catheter-where the mucosal surface has been breached. Other factors facilitating the initiation of mucosal infections are long-term antibiotic use (which reduces bacterial competition on the mucosal surfaces), extreme age, and use of prosthetics, such as dentures (Miramón et al. 2013).

In immunocompromised hosts or those on antibacterial treatments, Candida can proliferate. High proliferation results in biofilm formation giving rise to the superficial mucosal form of the disease. The biofilm produced can direct a more coordinated damaging effect on the host, which in some instances is able to rupture mucosal barriers (Ramage et al. 2009). Yeast cells associated with the biofilm can then systemically invade the host's bloodstream resulting in systemic pathogen spread (Uppuluri et al. 2010; Miramón et al. 2013). The yeast cells interact with the mucosal and systemic macrophages and neutrophils and, therefore, require a variety of virulence factors involved with macrophage survival and nutrient acquisition to remain viable (Miramón et al. 2013). Three key survival mechanisms will be discussed: evasion and escape, acidic/oxidative/hydrolytic survival, and nutrient acquisition.

Evasion of macrophage engulfment is a strategy that many fungal and bacterial pathogens adopt, reducing the chance of phagocytic destruction and proinflammatory cytokine production. Some pathogens limit phagocyte chemotaxis cues to prevent internalization, and recent work suggests that changes in C. albicans during the yeast-to-hyphal transition can limit phagocyte recruitment (Brothers et al. 2013). As with many fungal pathogens, C. albicans has been shown to mask the immunostimulatory $\beta$-glucan constituent of the cell wall via mannoproteins, thus reducing fungal recognition while promoting and maintaining an anti-inflammatory response (Fig. 2) (Wheeler et al. 2008). Ultimately, however, many yeast cells will still be engulfed by macrophages; hence, survival and replication or subsequent escape remain important features. C. albicans and C. glabrata actively limit phagosome maturation in macrophages to prevent acidification and limit hydrolytic attack (Fig. 2) (Fernandez-Arenas et al. 2009; Seider et al. 2011). Neither the mechanisms for maturation arrest nor its relative contribution to fungal survival are known, although blocking phagosome-lysosome maturation plays an important role for many intracellular pathogens (Fig. 2).

C. albicans yeast cells sense changes between the external and internal macrophage environment, and use this information to turn on an escape program that includes hyphal germination and induction of pyroptosis. Elevated $\mathrm{CO}_{2}$ levels, reduced oxygen levels, the presence of reactive oxygen species (ROS), and neutral $\mathrm{pH}$ are known cues of filamentation in yeast cells in vitro (Klengel et al. 2005; Vylkova et al. 2011). In vitro experiments suggest that $C$. albicans can germinate within macrophages to cause macrophage membrane rupture and eventual lysis (Fig. 2), allowing C. albicans to escape. Intriguingly, this macrophage lysis may be a result of pyroptosis instead of physical membrane rupture (Wellington et al. 2012). Although yeast-tohyphal germination of $C$. albicans inside macrophages at high yeast-to-macrophage ratios in vitro is dramatic, at lower ratios the activation of macrophages can restrict proliferation and morphogenesis of engulfed C. albicans (Calderone and Sturtevant 1994; Vázquez-Torres and Balish 1997). Recent work in vivo in the zebrafish infection model also suggests that macrophages are more active in restricting hyphal growth when in their natural context rather than in vitro (Brothers et al. 2011, 2013). Filamentation mutants and Candida species that do not filament, such as C. glabrata, are not always avirulent, 
A.S. Gilbert et al.

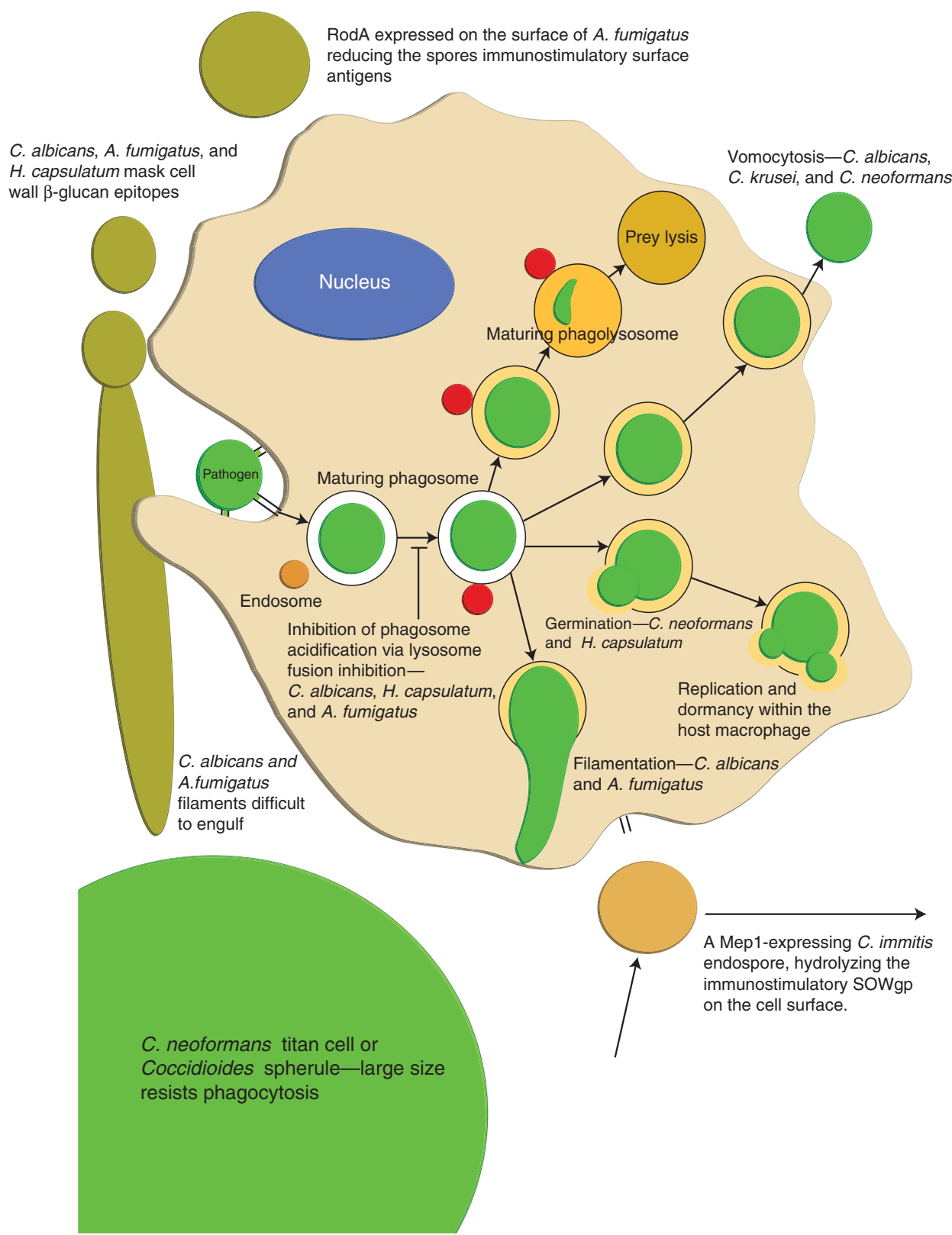

Figure 2. Diagrammatic representation of strategies used by different fungal species to avoid destruction by macrophages.

indicating that other mechanisms exist to allow survival, replication, and escape from within macrophages (see Lo et al. 1997; Lorenz et al. 2004). Indeed, recently, C. albicans and C. krusei yeast cells have also been shown to escape via a nonlytic process first identified in Cryptococcus neoformans, in which both fungus and macrophage are left intact postexpulsion (Fig. 2) (García-Rodas et al. 2011; Bain et al. 2012).

The C. albicans genome is rich in genes that, when transcribed, enable macrophage survival. Hoglp is a protein kinase activated by a diverse 
range of stressors, such as acidity, heavy metals, and osmolarity, and known to regulate genes in response to phagosomal conditions (Smith et al. 2004). Cap1p, the C. albicans homolog of Saccharomyces cerevisiae YAP1 (Enjalbert et al. 2003), is a transcription factor that induces genes involved in carbohydrate metabolism, drug resistance, antioxidant production, and energy production (Wang et al. 2006). The loss of Hog1p renders C. albicans very sensitive to phagocyte killing (Miramón et al. 2012), whereas a sixfold early activation of CAP1 has been shown in vitro in C. albicans when exposed to oxidative stress, generated via heat and osmotic shocks (Enjalbert et al. 2003). CAP1 is required for full virulence in a moth larva virulence model and for macrophage destruction in vitro, but unexpectedly is not required for virulence in the intravenous mouse candidiasis model (Patterson et al. 2013).

The copper and zinc containing superoxide dismutases, Sod1 and Sod4, are intracellular and extracellular superoxide dismutases, respectively (Hwang et al. 2002; Miramón et al. 2013). Both Sod 1 and Sod4 provide C. albicans yeast cells with protection from ROS by converting these species into hydrogen peroxide $\left(\mathrm{H}_{2} \mathrm{O}_{2}\right)$. Hydrogen peroxide is highly antimicrobial and thus Ctalp, a catalase enzyme secreted by C. albicans, converts $\mathrm{H}_{2} \mathrm{O}_{2}$ into water and oxygen, reducing the antimicrobial effect (Hwang et al. 2002; Mayer et al. 2013). $\mathrm{H}_{2} \mathrm{O}_{2}$ can also be dealt with by the glutathione peroxidases (Gpxs) that detoxify $\mathrm{H}_{2} \mathrm{O}_{2}$ by oxidizing the thiol groups of two glutathione molecules (Miramón et al. 2013). Superoxide dismutases, catalases, and glutathione peroxidases thus appear to work synergistically to reduce oxidative stress.

Reactive nitrogen species (RNS) are secreted into the phagosome by macrophages and are thought to create a fungistatic effect against Candida species, maintaining the phagocytosed fungi in a state of limbo, whereas more destructive antimicrobials are secreted leading to pathogen clearance. The C. albicans genome contains few genes able to neutralize the effects of nitric oxide (NO). Of the three flavohaemoglobins, enzymes secreted to convert NO to nitrate, one
(YHB1) is up-regulated on exposure to macrophages and appears to play a critical role in C. albicans defense against NO (Ullmann et al. 2004).

Once defensive strategies are in place, nutrient acquisition becomes the top priority, enabling growth and replication within macrophages. Macrophage phagosomes pose a nutritional challenge in which alternative sources of carbon, nitrogen, and trace elements must be used to promote growth (Lorenz et al. 2004). Needless to say, the genomes of C. albicans and C. glabrata are rife with genes for such an eventuality. C. albicans up-regulates genes involved in the glyoxylate cycle and gluconeogenesis (Lorenz et al. 2004), allowing 2-carbon usage from alternative sources, whereas down-regulating genes involved in glycolysis and protein synthesis to limit these processes that demand high energy and consume considerable levels of carbon and nitrogen (Fradin et al. 2005; Miramón et al. 2013). C. albicans also increases levels of enzymes in $\beta$-oxidation, presumably to take advantage of the relatively higher abundance of fatty acids within the phagosomal environment (Lorenz et al. 2004; Ramírez and Lorenz 2009). Similarly, C. glabrata up-regulates methylcitrate cycle genes in response to macrophages. This pathway enables the degradation of fatty acid chains, allowing lipids to be used as an alternative carbon source (Kaur et al. 2007; Miramón et al. 2013). Increased production of hexose transporter proteins and a maltose transporter proteins postmacrophage exposure further emphasizes the widespread genetic and metabolic shift required to maintain a steady carbon influx into the pathogen (Lorenz et al. 2004).

The up-regulation of amino acid biosynthetic pathways, in response to macrophage stressors, such as ROS, is common practice adopted by Candida species in response to nitrogen deprivation. Both C. glabrata and C. albicans up-regulate the arginine biosynthetic pathway, whereas C. glabrata also up-regulates lysine biosynthesis (Kaur et al. 2007; JiménezLópez et al. 2013). The increase in arginine biosynthesis creates $\mathrm{CO}_{2}$ and urea as waste products, increasing $\mathrm{pH}$ and potentially inducing filamentation in C. albicans, hence promot- 
A.S. Gilbert et al.

ing lytic escape via macrophage membrane rupture (Vylkova et al. 2011). General amino acid permease genes are more highly transcribed in the phagosome environment in both $C$. albicans and C. glabrata (Lorenz et al. 2004), further highlighting the importance of nitrogen acquisition in the parasitic intracellular lifecycle.

\section{Aspergillus fumigatus}

The ascomycete A. fumigatus is a common worldwide saprotroph found abundantly in compost heaps, playing a vital role in nutrient recycling and organic decomposition. It is also, however, the cause of life-threatening aspergillosis in immunocompromised individuals. A. fumigatus exposure is unavoidable with asexual conidia ubiquitous in the air and commonly inhaled; 200-300 conidia are inhaled per person per day (Latge 1999; Morton et al. 2012). In immunocompromised hosts, such as those with neutropenia or on medication to inhibit the activity of their immune system, A. fumigatus has the ability to cause invasive aspergillosis, the most severe and life-threatening form of the disease (Mansour et al. 2012). According to Pappas et al. (2010), 10\% of all bone marrow transplant patients develop invasive aspergillosis.

The molecular and genetic evolution of the pathogenicity of A. fumigatus suggests that adaptations concerned with "compost heap" survival are transferable to vertebrate macrophage survival. Two good examples of this are: (1) the evolution of thermostable ribosomes and heatshock proteins enabling appropriate protein translation at elevated temperatures, even up to $55-70^{\circ} \mathrm{C}$ in self-heating compost heaps (Nierman et al. 2005), and (2) the evolution of elastases and other proteases, capable of hydrolyzing protein components of the compost heap for amino acid assimilation and hydrolyzing elastin proteins in the host's lung tissue, increasing pathogenicity (Blanco et al. 2002).

On entry into the lung, Aspergillus conidia can be recognized and phagocytosed by host white blood cells. On engulfment, however, an unknown mechanism inhibits acidification/ maturation of the phagosome, thus maintaining a neutral $\mathrm{pH}$ and promoting pathogen sur- vival. Subsequent hyphal growth then lyses the macrophage (Morton et al. 2012). The dihydroxynaphthalene (DHM) melanin coat on the conidial surface, which provides the green-grayish color, is required for avoiding lysosomal fusion, although the underlying mechanism remains unclear (Thywissen et al. 2011). This finding extends the known functions of melanin, which is more commonly used to provide DNA protection from ultraviolet radiation in mammals (Meredith and Riesz 2004) and protection against reactive radicals in fungi (Heinekamp et al. 2013).

A. fumigatus conidia synthesizes a $\operatorname{RodA}$ hydrophobin (a hydrophobic protein) that is expressed on the surface of the cells. This hydrophobin conceals immunostimulatory cell-surface proteins and carbohydrates, resulting in poor fungal recognition by the cells of the innate immune system (Fig. 2) (Aimanianda et al. 2009). Evidence suggests that RodA has also been implicated in the suppression of macrophage maturation, although how this is achieved remains unclear (Aimanianda et al. 2009).

A. fumigatus relies on the secretion of secondary metabolites, part of a multiplex of adaptations, which allows it to occupy the specialized niche of the phagosome. A distinct set of these secondary metabolites includes a plethora of toxins that often have immunosuppressive characteristics, inhibiting macrophage function (Latge 1999). The most well-known secreted toxic compound produced by Aspergillus is gliotoxin, which inhibits phagocytosis and induces macrophage apoptosis (Latge 1999). Aspergillus also encodes a major allergen known as ribotoxin, a toxin able to cleave a single phosphodiester bond of the 28S rRNA of eukaryote ribosomes, hence contributing toward virulence by reducing host protein translation (Nierman et al. 2005).

Once survival mechanisms are implemented within the macrophage, $A$. fumigatus needs to extract organic materials that can be catabolized into usable organic biological compounds, promoting growth and replication. Aspergillus has a wide range of transporter proteins for this process. For instance, iron-chelating siderophores are secreted into the surrounding en- 
vironment, whereas iron-consuming processes are inhibited (Schrettl and Haas 2011). Siderophores have an extremely high affinity for iron and are able to bind to iron freely available within the environment but also remove it from other iron binding compounds, such as hemoglobin and transferrin. The iron-bound siderophores are then reabsorbed into the fungi via the siderophore iron transporter (SIT) complex to be redistributed around the fungi for further metabolism, aiding pathogen survival (Schrettl and Haas 2011).

\section{Cryptococcus neoformans/gattii}

The encapsulated yeast basidiomycete, C. neoformans, is an opportunistic and lethal fungal pathogen able to cause cryptococcosis in immunocompromised/immunosuppressed individuals, such as those suffering from HIV/ AIDS or those administered immunosuppressive therapies, respectively (Johnston and May 2013). The Cryptococcus genus has a second pathogenic species, gattii, which alarmingly has been associated with infections in immunocompetent hosts (Pacific Northwest outbreak) (Hoang et al. 2004; Chaturvedi and Chaturvedi 2011). One million patients are diagnosed with cryptococcosis per annum of which $\sim 650,000$ cases are lethal; $80 \%$ of these cases are in subSaharan Africa (Park et al. 2009). Treatment is complicated as symptoms are often observed late after disease onset-often at the cryptococcal meningoencephalitis stage (Johnston and May 2013).

The desiccated yeast cells or basidiospores of Cryptococcus are thought to be the infectious agents of cryptococcosis. The inhaled spores travel through the lungs, ultimately entering the alveoli. The spores then interact with the alveolar macrophages; cells responsible for protecting the host from potential inhaled pathogens by phagocytosing and destroying foreign bodies (Velagapudi et al. 2009; Johnston and May 2013). This initial vital interaction between cryptococcal basidiospores and the innate immune defense of the alveolar macrophages determines how the disease will progress (Voelz et al. 2009). Ideally, these spores are phagocy- tosed by the macrophages and the spores destroyed by the antimicrobial environment created. Unfortunately, C. neoformans and C. gattii have evolved mechanisms that resist destruction by macrophages, resulting in either escape or dormancy within the macrophage (Johnston and May 2013). The natural environment for Cryptococcus species is soil, which is often rich in predatory amoebae that use phagocytosis to engulf cryptococcal spores as a food source. Thus, a compelling hypothesis is that cryptococci have evolved mechanisms to avoid amoebal predation and that these survival attributes are therefore transferable when spores find their way into a vertebrate host (Steenbergen et al. 2001; Derengowski et al. 2013). The bacterial organism that causes legionnaires disease, Legionella pneumophilia, is thought to have evolved in a similar way (Smith and May 2013).

Cryptococci have several features that, together, facilitate avoidance, survival, or replication within phagocytes. First, a polysaccharide coat surrounds the basidiospores of $C$. neoformans acting as both a chemical and physical barrier to fungal recognition by the macrophage (Bose et al. 2003). The capsule is typically 4- to $6-\mu \mathrm{m}$ thick and is composed primarily of the following three constituents: glucuronoxylomannan $(90 \%-95 \%)$, glucuronoxylomannogalactan (5\%-10\%), and mannoproteins (Doering 2009). The capsule can also be shed to avoid macrophage attachment and to disrupt macrophage function postengulfment. Another unique and unusual technique adopted by C. neoformans is the ability for up to $20 \%$ of the population to become "titan cells" on exposure to the pulmonary environment of the host (Fig. 2). The size of these cells varies from 50 to $100 \mu \mathrm{m}$ in diameter, each with a varying degree of capsule thickness. These titan cells are too large to be phagocytosed and in addition provide phagocytosis resistance to adjacent normal sized yeast cells via an unknown mechanism (Okagaki et al. 2010, 2012; Zaragoza and Nielsen 2013). Similarly, App1 (antiphagocytic protein 1) is a secreted protein that inhibits complement-mediated phagocytosis (Stano et al. 2009), whereas transcriptional regulators, such as Gat201 and Gat204, together with the protein 
A.S. Gilbert et al.

Blp1, are all involved in the phagocytosis resistance of cryptococci (Liu et al. 2008).

The stringent avoidance strategies described above cannot prevent phagocytosis indefinitely; and a substantial proportion of inhaled cryptococci are ultimately phagocytosed, especially in the presence of opsonin. On internalization, however, C. neoformans uses a wide variety of defense strategies to enable growth and replication within the macrophage, an interaction first witnessed in 1973 by Diamond and Bennett. As with all parasitic fungal (and bacterial) pathogens, C. neoformans must resist antimicrobial attack and directly extract nutrients from the surrounding environment. Phagosome maturation is an important step required to create the antimicrobial environment involving the fusion of multiple vesicles and the fusion of the lysosome. A respiratory burst is the first stage of macrophage maturation followed by acidification of the phagosome and secretion of acid-dependent proteases (Fairn and Grinstein 2012). At least some aspects of phagosomal maturation appear to proceed normally on internalization of cryptococci, with the phagosome $\mathrm{pH}$ dropping to at least $\mathrm{pH} 5$ (Levitz et al. 1999). However, the thick polysaccharide capsule and melanin coat (Zhu et al. 2001) absorb reactive oxygen species (Zaragoza et al. 2008), whereas several other genes are also involved in defense against ROS. For instance, SOD1 encodes a secreted superoxide dismutase enzyme, which converts ROS into hydrogen peroxide and water (see Histoplasma capsulatum for more detail). URE1 encodes a urease enzyme, involved in the hydrolysis of host and pathogen-produced urea into ammonia, resulting in the $\mathrm{pH}$ neutralization of the phagosome (see Coccidiodes). Two other genes associated with RNS and ROS resistance are FHB1 (flavohemoglobin 1) and TSA1 (thiol-specific antioxidant 1), respectively-see Candida (Brown et al. 2007; Johnston and May 2013; Smith and May 2013).

Cryptococcus has the ability to escape the macrophage by inducing macrophage lysis but also has the ability to escape via a nonlytic process known as vomocytosis (Fig. 2) (Alvarez and Casadevall 2006; Ma et al. 2006). The mechanism behind lytic escape is poorly understood because Cryptococcus has no known poreforming protein used by some other pathogens to punch holes into the host's plasma membrane (Johnston and May 2013). One possibility is that the virulence factor phospholipase B is important for lytic escape, although phospholamban (PLB) activity alone is unlikely to perforate the cellular membrane of the macrophage sufficiently (Johnston and May 2013). It is also possible that lysis results from excessive fungal proliferation causing physical stress and the eventual rupture of the cellular membrane (Johnston and May 2013).

Vomocytosis is the process of fungal expulsion from the macrophage without causing lysis of the host cell (Alvarez and Casadevall 2006; Ma et al. 2006). Recently, similar processes have been noted in C. albicans (Bain et al. 2012) and C. krusei (García-Rodas et al. 2011). It is likely that nonlytic escape offers a distinct advantage by minimizing proinflammatory signaling and thus ensuring that immune activity is kept to a minimal level.

Vomocytosis is a highly regulated, complicated process similar to cellular exocytosis requiring intense cellular signaling and microtubule activity, although the molecular process is poorly understood. To date, the only pathogen factor known to contribute to vomocytosis is CnPlb1, because loss of this enzyme reduces but does not entirely block escape (Chayakulkeeree et al. 2011). Interestingly, phagocytic cells have an actin-dependent mechanism to block vomocytosis in cryptococci (Johnston and May 2010), although whether this process blocks the escape of other pathogens remains unknown.

\section{Coccidiodes posadasii/immitis}

C. posadasii and C. immitis are dimorphic fungal pathogens responsible for coccidioidomycosis, a systemic infection commonly known as "valley fever" (Borchers and Gershwin 2010; Smith and May 2013). Endemic regions include the semiarid southern United States (Nevada, Utah, and Arizona) and regions of South America (northern Mexico) (Welsh et al. 2012). In 
immunocompetent patients, coccidioidomycosis primarily manifests as an asymptomatic infection but can develop into a dry cough. As with many other fungal pathogens, immunocompromised patients and pregnant women are at greater risk of being dangerously infected from a disseminated form (meningitis) of the disease (Borchers and Gershwin 2010; Welsh et al. 2012).

The natural environment of Coccidiodes is in semiarid alkaline sandy clay soils (Welsh et al. 2012). The mycelia grow saprophytically in the soil producing the infectious arthroconidia that are considered to be small enough to be aerosolized and inhaled by the host during dust storms common to the region (Welsh et al. 2012). On entry into the host, gene expression within the arthroconidia rapidly alters to transform it into a large $(60-100 \mu \mathrm{m})$ endosporulating spherule (Fig. 2) that cannot be phagocytosed owing to its size (Frey and Drutz 1986). The spherule contains up to 300 small infectious endospores that are released, leading to dissemination around the body (Smith and May 2013). Alveolar macrophages and neutrophils are able to phagocytose both arthroconidia and endospores, but phagocytosed particles are difficult to destroy even for immunocompetent patients, partially because lysosome fusion is inhibited (Beaman and Holmberg 1980).

The spherule outer wall glycoprotein (SOWgp) is an important, immunostimulatory glycoprotein expressed on the surface of the Coccidiodes spherules and endospores (Hung et al. 2000). Hung et al. found that the SOWgp on the surface of spherules causes the activation of the $\mathrm{Th}_{2}$-directed immune response and $\mathrm{Th}_{2}$-type cytokine (IL-6 and IL-10) secretion, providing a significant advantage to the pathogen (Hung et al. 2007). This method of immunomodulation means that, once the endospores are released, the immune system is poorly equipped to attack them. However, SOWgp is immunostimulatory on smaller endospores, potentially resulting in phagocytosis. To avoid this, endospores secrete a metalloproteinase, Mep1, which hydrolyses surface-bound SOWgp, reducing phagocytosis (Fig. 2) (Hung et al. 2005, 2007).
Even following phagocytosis, Coccidiodes is able to resist killing by several mechanisms. Gonzalez et al. (2011) showed the presence of a soluble factor produced by Coccidiodes, which blocks the action of host phagocyte nitric oxide. In addition, the pathogen secretes urease, which hydrolyses both pathogen and host-derived urea into ammonia, increasing the phagosomal $\mathrm{pH}$ and generating a $\mathrm{pH}$ neutral environment (Mirbod-Donovan et al. 2006). Up-regulation of urease synthesis genes has been noted in the parasitic spherule phase of both $C$. posadasii and C. immitis (Whiston et al. 2012).

Whiston et al. (2012) performed transcriptomic analysis comparing gene transcription of both C. immitis and C. posadasii while in the saprobic mycelial natural growth phase and the pathogenic parasitic spherule phase. Phasespecific up-regulation of genes was identified, highlighting genetic transcripts that were upregulated in the pathogenic including AGS1 $(\alpha$-(1,3)-glucan synthase). $\alpha$-Glucans act to mask the immunostimulatory $\beta$-glucans found on the fungal cell wall, reducing fungal recognition and interaction by the innate immune system (Whiston et al. 2012), as is the case for H. capsulatum (Rappeleye et al. 2007).

\section{H. capsulatum}

H. capsulatum is a thermally stable dimorphic fungus and the causative agent of the life-threatening disease, histoplasmosis. Histoplasmosis is primarily a respiratory disease able to infect both immunocompetent and immunocompromised hosts and is predominantly found in the United States, where, in endemic regions, exposure is thought to be as high as $80 \%$, with significant morbidity in 50,000 immunocompetent hosts per annum (Edwards et al. 1969; Chu et al. 2006). As with many fungal diseases, cases of histoplasmosis are on the increase (McNeil et al. 2001).

An $H$. capsulatum infection initiates when the mycelial-produced microconidia $(2-6 \mu \mathrm{m}$ in diameter) are inhaled into the lungs of the mammalian host (Helmbright and Larsh 1952). On entry into the host, the increase in temperature up to $37^{\circ} \mathrm{C}$ triggers a dimorphic 
A.S. Gilbert et al.

switch into the yeast form (Inglis et al. 2013). Although yeast cells are rapidly engulfed by neutrophils and alveolar macrophages of the host's innate immune system, defense mechanisms allow the organism to survive and replicate within the macrophage environment (Inglis et al. 2013), and successful clearance of the infection requires the adaptive immune response to enhance the antifungal activity of the infected macrophages (Kroetz and Deepe 2012).

A major factor enabling $H$. capsulatum survival is its ability to manipulate the phagosome to maintain an internal $\mathrm{pH}$ of 6.5 , reducing the activity of acid-dependent hydrolytic proteases and generating a more neutral and growth-promoting environment (Strasser et al. 1999; Smith and May 2013). At the same time, the pathogen up-regulates a siderophore biosynthetic cluster consisting of the genes ABC1, SID1, SID3, SID4, and OXR1 (Inglis et al. 2013), which aid in iron scavenging in an analogous way to that which occurs in Aspergillus species (Schrettl and Haas 2011). Histoplasma also secretes two catalases, CatB and CatP. These convert antimicrobial hydrogen peroxide $\left(\mathrm{H}_{2} \mathrm{O}_{2}\right)$ to water and oxygen (Holbrook et al. 2013). CatP acts intracellularly while CatB is secreted and has an association with the cell wall, in which it acts downstream from the secreted superoxide dismutase Sod3 (Youseff et al. 2012; Holbrook et al. 2013).

The transcriptomic study by Inglis et al. (2013) has also highlighted other genes whose products may play a role in macrophage survival and replication. LDF1 gene encodes a protein required to lyse macrophages, although the underlying molecular mechanism is poorly understood; whereas LYP1 gene encodes a predicted membrane transporter protein that may potentially facilitate amino acid transport, such as lysine or cysteine.

\section{SUMMARY}

All of the fungal pathogens described above have the genetic and metabolic machinery to survive and replicate within human macrophages, thus enhancing their pathogenicity and virulence. Many of the pathogens share common features associated with macrophage survival and repli- cation, such as cell-surface modification strategies (SOWgp, $\alpha$-glucan, Rod A, polysaccharide capsule), to avoid pathogen recognition and ultimately phagocytosis and ROS resistance (superoxide dismutases and catalases, polysaccharide coat), reducing the antimicrobial activity of the macrophage and the utilization of alternative nutrient-acquisition pathways to enable survival within the nutrient-sparse macrophage environment. Inhibiting the defensive strategies described above may enable the macrophage to overwhelm the pathogen, hence removing the threat of systemic infection. Current research in this field is targeted to the common and unique defensive strategies of the individual pathogens.

\section{ACKNOWLEDGMENTS}

We gratefully acknowledge the May and Wheeler labs for their input into this chapter and, in particular, Nadine Nicke for her artistic expertise in preparing Figure 1. R.C.M. is supported by the Medical Research Council, Lister Institute for Preventive Medicine, and the $\mathrm{Na}$ tional Institute for Health Research. A.S.G. is funded by a BBSRC doctoral training fellowship via the Midlands Integrative Biosciences Training Program. R.T.W. is supported by National Institutes of Health (NIH) Grants 5P20RR 016463, 8P20GM103423, and R15AI094406 and the United States Department of Agriculture (USDA) Project \#ME0-H-1-00517-13.

\section{REFERENCES}

Aimanianda V, Bayry J, Bozza S, Kniemeyer O, Perruccio K, Elluru SR, Clavaud C, Paris S, Brakhage AA, Kaveri SV, et al. 2009. Surface hydrophobin prevents immune recognition of airborne fungal spores. Nature 460: 1117-1121.

Alvarez M, Casadevall A. 2006. Phagosome extrusion and host-cell survival after Cryptococcus neoformans phagocytosis by macrophages. Curr Biol 16: 2161-2165.

Bain J, Lewis L, Okai B, Quinn J, Gow N, Erwig L. 2012. Non-lytic expulsion/exocytosis of Candida albicans from macrophages. Fungal Genet Biol 49: 677-678.

Beaman L, Holmberg C. 1980. In vitro response of alveolar macrophages to infection with Coccidioides immitis. Infect Immun 28: 594-600.

Biswas S, Mantovani A. 2010. Macrophage plasticity and interaction with lymphocyte subsets: Cancer as a paradigm. Nat Immunol 11: 889-896. 
Blanco J, Hontecillas R, Bouza E, Blanco I, Pelaez T, Munoz P, Molina J, García M. 2002. Correlation between the elastase activity index and invasiveness of clinical isolates of Aspergillus fumigatus. J Clin Microbiol 40: 1811-1813.

Borchers A, Gershwin M. 2010. The immune response in Coccidioidomycosis. Autoimmun Rev 10: 94-102.

Bose I, Reese A, Ory J, Janbon G, Doering T. 2003. A yeast under cover: The capsule of Cryptococcus neoformans. Eukaryot Cell 2: 655-663.

Brothers KM, Newman ZR, Wheeler RT. 2011. Live imaging of disseminated candidiasis in zebrafish reveals role of phagocyte oxidase in limiting filamentous growth. $E u$ karyot Cell 10: 932-944.

Brothers KM, Gratacap RL, Barker SE, Newman ZR, Norum A, Wheeler RT. 2013. NADPH oxidase-driven phagocyte recruitment controls Candida albicans filamentous growth and prevents mortality. PLoS Pathog 9: e1003634.

Brown S, Campbell L, Lodge J. 2007. Cryptococcus neoformans, a fungus under stress. Curr Opin Microbiol 10: 320-325.

Brown GD, Denning DW, Gow NA, Levitz SM, Netea MG White TC. 2012. Hidden killers: Human fungal infections. Sci Transl Med 4: 165rv113.

Calderone R, Sturtevant J. 1994. Macrophage interactions with Candida. Immunol Ser 60: 505-515.

Chaturvedi V, Chaturvedi S. 2011. Cryptococcus gattii: A resurgent fungal pathogen. Trends Microbiol 19: 564571.

Chayakulkeeree M, Johnston S, Oei J, Lev S, Williamson P, Wilson C, Zuo X, Leal A, Vainstein M, Meyer W, et al. 2011. SEC14 is a specific requirement for secretion of phospholipase B1 and pathogenicity of Cryptococcus neoformans. Mol Microbiol 80: 1088-1101.

Chen H, Langer R, Edwards D. 1997. A film tension theory of phagocytosis. J Colloid Interface Sci 190: 118-133.

Chu J, Feudtner C, Heydon K, Walsh T, Zaoutis T. 2006. Hospitalizations for endemic mycoses: A populationbased national study. Clin Infect Dis 42: 822-825.

Derengowski L, Paes H, Albuquerque P, Tavares A, Fernandes L, Silva-Pereira I, Casadevall A. 2013. The transcriptional response of Cryptococcus neoformans to ingestion by Acanthamoeba castellanii and macrophages provides insights into the evolutionary adaptation to the mammalian host. Eukaryot Cell 12: 761-774.

Diamond R, Bennett J. 1973. Growth of Cryptococcus neoformans within human macrophages in vitro. Infect Immun 7: 231-236.

Doering T. 2009. How sweet it is! Cell wall biogenesis and polysaccharide capsule formation in Cryptococcus neoformans. Annu Rev Microbiol 63: 223-247.

Edwards L, Acquaviv FA, Levesay V, Cross F, Palmer C. 1969. An atlas of sensitivity to tuberculin, PPD-B, and histoplasmin in the United States. Am Rev Respir Dis 99: 1132.

Enjalbert B, Nantel A, Whiteway M. 2003. Stress-induced gene expression in Candida albicans: Absence of a general stress response. Mol Biol Cell 14: 1460-1467.

Fairn G, Grinstein S. 2012. How nascent phagosomes mature to become phagolysosomes. Trends Immunol 33: 397-405.
Fernandez-Arenas E, Bleck C, Nombela C, Gil C, Griffiths G Diez-Orejas R. 2009. Candida albicans actively modulates intracellular membrane trafficking in mouse macrophage phagosomes. Cell Microbiol 11: 560-589.

Flannagan RS, Jaumouillé V, Grinstein S. 2012. The cell biology of phagocytosis. Annu Rev Pathol 7: 61-98.

Fradin C, De Groot P, MacCallum D, Schaller M, Klis F, Odds F, Hube B. 2005. Granulocytes govern the transcriptional response, morphology and proliferation of Candida albicans in human blood. Mol Microbiol 56: 397-415.

Frey CL, Drutz DJ. 1986. Influence of fungal surface components on the interaction of Coccidioides immitis with polymorphonuclear neutrophils. J Infect Dis 153: 933943.

García-Rodas R, González-Camacho F, Rodríguez-Tudela JL, Cuenca-Estrella M, Zaragoza O. 2011. The interaction between Candida krusei and murine macrophages results in multiple outcomes, including intracellular survival and escape from killing. Infect Immun 79: 2136-2144.

Gonzalez A, Hung C, Cole G. 2011. Coccidioides releases a soluble factor that suppresses nitric oxide production by murine primary macrophages. Microb Pathog 50: 100108.

Gordon S, Martinez F. 2010. Alternative activation of macrophages: Mechanism and functions. Immunity 32: 593 604.

Heinekamp T, Thywissen A, Macheleidt J, Keller S, Valiante V, Brakhage AA. 2013. Aspergillus fumigatus melanins: Interference with the host endocytosis pathway and impact on virulence. Front Microbiol 3: 440.

Helmbright A, Larsh H. 1952. Size of the spores of Histoplasma capsulatum. Proc Soc Exp Biol Med 81: 550-551.

Hoang L, Maguire J, Doye P, Fyfe M, Roscoe D. 2004. Cryptococcus neoformans infections at Vancouver Hospital and Health Sciences Centre (1997-2002): Epidemiology, microbiology and histopathology. J Med Microbiol 53: 935-940.

Holbrook E, Smolnycki K, Youseff B, Rappleye C. 2013. Redundant catalases detoxify phagocyte reactive oxygen and facilitate Histoplasma capsulatum pathogenesis. Infect Immun 81: 2334-2346.

Hung C, Ampel N, Christian L, Seshan K, Cole G. 2000. A major cell surface antigen of Coccidioides immitis which elicits both humoral and cellular immune responses. Infect Immun 68: 584-593.

Hung C, Seshan K, Yu J, Schaller R, Xue J, Basrur V, Gardner M, Cole G. 2005. A metalloproteinase of Coccidioides posadasii contributes to evasion of host detection. Infect Immun 73: 6689-6703.

Hung C, Xue J, Cole G, Clemons K, LaniadoLaborin R, Stevens D. 2007. Virulence mechanisms of Coccidioides: Coccidioidomycosis: Sixth International Symposium. Ann NY Acad Sci 1111: 225-235.

Hwang C, Rhie G, Oh J, Huh W, Yim H, Kang S. 2002. Copper- and zinc-containing superoxide dismutase $(\mathrm{Cu} / \mathrm{ZnSOD})$ is required for the protection of Candida albicans against oxidative stresses and the expression of its full virulence. Microbiology 148: 3705-3713.

Inglis DO, Voorhies M, Hocking Murray DR, Sil A. 2013. Comparative transcriptomics of infectious spores from the fungal pathogen Histoplasma capsulatum reveals a 
A.S. Gilbert et al.

core set of transcripts that specify infectious and pathogenic states. Eukaryot Cell 12: 828-852.

Jiménez-López C, Collette JR, Brothers KM, Shepardson KM, Cramer RA, Wheeler RT, Lorenz MC. 2013. Candida albicans induces arginine biosynthetic genes in response to host-derived reactive oxygen species. Eukaryot Cell 12: 91-100.

Johnston S, May RC. 2010. The human fungal pathogen Cryptococcus neoformans escapes macrophages by a phagosome emptying mechanism that is inhibited by Arp2/3 complex-mediated actin polymerisation. PLoS Pathog 6: e1001041.

Johnston S, May RC. 2013. Cryptococcus interactions with macrophages: Evasion and manipulation of the phagosome by a fungal pathogen. Cell Microbiol 15: 403-411.

Kaur R, Ma B, Cormack B. 2007. A family of glycosylphosphatidylinositol-linked aspartyl proteases is required for virulence of Candida glabrata. Proc Natl Acad Sci 104: $7628-7633$.

Kinchen J, Ravichandran K. 2008. Phagosome maturation Going through the acid test. Nat Rev Mol Cell Biol 9: 781795.

Klengel T, Liang W, Chaloupka J, Ruoff C, Schroppel K, Naglik J, Eckert S, Mogensen E, Haynes K, Tuite M, et al. 2005. Fungal adenylyl cyclase integrates $\mathrm{CO}_{2}$ sensing with cAMP signaling and virulence. Curr Biol 15: 2177 2177.

Kroetz D, Deepe G. 2012. The role of cytokines and chemokines in Histoplasma capsulatum infection. Cytokine 58: 112-117.

Krombach F, Münzing S, Allmeling AM, Gerlach JT, Behr J, Dörger M. 1997. Cell size of alveolar macrophages: An interspecies comparison. Environ Health Perspect 105: 1261-1263.

Latge J. 1999. Aspergillus fumigatus and aspergillosis. Clin Microbiol Rev 12: 310.

Levitz S, Nong S, Seetoo K, Harrison T, Speizer R, Simons E. 1999. Cryptococcus neoformans resides in an acidic phagolysosome of human macrophages. Infect Immun 67: 885-890.

Lionakis MS, Swamydas M, Fischer BG, Plantinga TS, Johnson MD, Jaeger M, Green NM, Masedunskas A, Weigert $\mathrm{R}$, Mikelis C, et al. 2013. $\mathrm{CX}_{3}$ CR1-dependent renal macrophage survival promotes Candida control and host survival. J Clin Invest 123: 5035-5051.

Liu O, Chun C, Chow E, Chen C, Madhani H, Noble S. 2008. Systematic genetic analysis of virulence in the human fungal pathogen Cryptococcus neoformans. Cell 135: 174-188.

Lo HJ, Köhler JR, DiDomenico B, Loebenberg D, Cacciapuoti A, Fink GR. 1997. Nonfilamentous C. albicans mutants are avirulent. Cell 90: 939-949.

Lorenz M, Bender J, Fink G. 2004. Transcriptional response of Candida albicans upon internalization by macrophages. Eukaryot Cell 3: 1076-1087.

Ma H, Croudace J, Lammas D, May RC. 2006. Expulsion of live pathogenic yeast by macrophages. Curr Biol 16: 2156-2160.

Mansour M, Tam J, Vyas J, Clemons K, Perlin D, Richardson M. 2012. The cell biology of the innate immune response to Aspergillus fumigatus. Ann NY Acad Sci 1273: 78-84.
Mayer F, Wilson D, Hube B. 2013. Candida albicans pathogenicity mechanisms. Virulence 4: 119-128.

McNeil M, Nash S, Hajjeh R, Phelan M, Conn L, Plikaytis B, Warnock D. 2001. Trends in mortality due to invasive mycotic diseases in the United States, 1980-1997. Clin Infect Dis 33: 641-647.

Meredith P, Riesz J. 2004. Radiative relaxation quantum yields for synthetic eumelanin. Photochem Photobiol 79: 211-216.

Miramón P, Dunker C, Windecker H, Bohovych IM, Brown AJ, Kurzai O, Hube B. 2012. Cellular responses of Candida albicans to phagocytosis and the extracellular activities of neutrophils are critical to counteract carbohydrate starvation, oxidative and nitrosative stress. PLoS ONE 7: e52850.

Miramón P, Kasper L, Hube B. 2013. Thriving within the host: Candida spp. interactions with phagocytic cells. Med Microbiol Immunol 202: 183-195.

Mirbod-Donovan F, Schaller R, Hung C, Xue J, Reichard U, Cole G. 2006. Urease produced by Coccidioides posadasii contributes to the virulence of this respiratory pathogen. Infect Immun 74: 504-515.

Morton CO, Bouzani M, Loeffler J, Rogers TR. 2012. Direct interaction studies between Aspergillus fumigatus and human immune cells; what have we learned about pathogenicity and host immunity? Front Microbiol 3: 413.

Nierman W, Pain A, Anderson M, Wortman J, Kim H, Arroyo J, Berriman $\mathrm{M}$, Abe $\mathrm{K}$, Archer D, Bermejo $\mathrm{C}$, et al. 2005. Genomic sequence of the pathogenic and allergenic filamentous fungus Aspergillus fumigatus. Nature 438: $1151-1156$.

Okagaki L, Nielsen K. 2012. Titan cells confer protection from phagocytosis in Cryptococcus neoformans infections. Eukaryot Cell 11: 820-826.

Okagaki L, Strain A, Nielsen J, Charlier C, Baltes N, Chretien F, Heitman J, Dromer F, Nielsen K. 2010. Cryptococcal cell morphology affects host cell interactions and pathogenicity. PLoS Pathog 6: e1000953.

Pappas P, Alexander B, Andes D, Hadley S, Kauffman C, Freifeld A, Anaissie E, Brumble L, Herwaldt L, Ito J, et al. 2010. Invasive fungal infections among organ transplant recipients: Results of the Transplant-Associated Infection Surveillance Network (TRANSNET). Clin Infect Dis 50: 1101-1111.

Park B, Wannemuehler K, Marston B, Govender N, Pappas P, Chiller T. 2009. Estimation of the current global burden of cryptococcal meningitis among persons living with HIV/AIDS. Aids 23: 525-530.

Patterson MJ, McKenzie CG, Smith DA, da Silva Dantas A, Sherston S, Veal EA, Morgan BA, Maccallum DM, Erwig LP, Quinn J. 2013. Ybp1 and Gpx3 signaling in Candida albicans govern hydrogen peroxide-induced oxidation of the Cap1 transcription factor and macrophage escape. Antioxid Redox Signal 19: 2244-2260.

Ramage G, Mowat E, Jones B, Williams C, Lopez-Ribot J. 2009. Our current understanding of fungal biofilms. Crit Rev Microbiol 35: 340-355.

Ramírez MA, Lorenz MC. 2009. The transcription factor homolog CTF1 regulates $\beta$-oxidation in Candida albicans. Eukaryot Cell 8: 1604-1614. 
Rappleye C, Eissenberg L, Goldman W. 2007. Histoplasma capsulatum $\alpha$ - $(1,3)$-glucan blocks innate immune recognition by the $\beta$-glucan receptor. Proc Natl Acad Sci 104: $1366-1370$.

Schrettl M, Haas H. 2011. Iron homeostasis-Achilles' heel of Aspergillus fumigatus? Curr Opin Microbiol 14: 400-405.

Scully C, Elkabir M, Samaranayake L. 1994. Candida and oral candidosis: A review. Crit Rev Oral Biol Med 5: 125157.

Seider K, Brunke S, Schild L, Jablonowski N, Wilson D, Majer O, Barz D, Haas A, Kuchler K, Schaller M, et al. 2011. The facultative intracellular pathogen Candida glabrata subverts macrophage cytokine production and phagolysosome maturation. J Immunol 187: 3072-3086.

Smith LM, May RC. 2013. Mechanisms of microbial escape from phagocyte killing. Biochem Soc Trans 41: 475-490.

Smith D, Nicholls S, Morgan B, Brown A, Quinn J. 2004. A conserved stress-activated protein kinase regulates a core stress response in the human pathogen Candida albicans. Mol Biol Cell 15: 4179-4190.

Stano P, Williams V, Villani M, Cymbalyuk E, Qureshi A, Huang Y, Morace G, Luberto C, Tomlinson S, Del Poeta M. 2009. App1: An antiphagocytic protein that binds to complement receptors 3 and 2. J Immunol 182: 84-91.

Steenbergen JN, Shuman HA, Casadevall A. 2001. Cryptococcus neoformans interactions with amoebae suggest an explanation for its virulence and intracellular pathogenic strategy in macrophages. Proc Natl Acad Sci 98: 15245 15250.

Strasser J, Newman S, Ciraolo G, Morris R, Howell M, Dean G. 1999. Regulation of the macrophage vacuolar ATPase and phagosome-lysosome fusion by Histoplasma capsulatum. J Immunol 162: 6148-6154.

Thywissen A, Heinekamp T, Dahse HM, Schmaler-Ripcke J, Nietzsche S, Zipfel PF, Brakhage AA. 2011. Conidial dihydroxynaphthalene melanin of the human pathogenic fungus Aspergillus fumigatus interferes with the host endocytosis pathway. Front Microbiol 2: 96.

Ullmann B, Myers H, Chiranand W, Lazzell A, Zhao Q, Vega L, Lopez-Ribot J, Gardner P, Gustin M. 2004. Inducible defense mechanism against nitric oxide in Candida albicans. Eukaryotic Cell 3: 715-723.

Uppuluri P, Chaturvedi A, Srinivasan A, Banerjee M, Ramasubramaniam A, Kohler J, Kadosh D, Lopez-Ribot J. 2010. Dispersion as an important step in the Candida albicans biofilm developmental cycle. PLoS Pathog 6 e1000828.
Survival and Replication within Macrophages

Vázquez-Torres A, Balish E. 1997. Macrophages in resistance to candidiasis. Microbiol Mol Biol Rev 61: 170-192.

Velagapudi R, Hsueh Y, Geunes-Boyer S, Wright J, Heitman J. 2009. Spores as infectious propagules of Cryptococcus neoformans. Infect Immun 77: 4345-4355.

Voelz K, Lammas D, May RC. 2009. Cytokine signaling regulates the outcome of intracellular macrophage parasitism by Cryptococcus neoformans. Infect Immun 77: 34503457.

Vylkova S, Carman A, Danhof H, Collette J, Zhou H, Lorenz M. 2011. The fungal pathogen Candida albicans autoinduces hyphal morphogenesis by raising extracellular pH. MBio 2: e00055-11.

Wang Y, Cao Y, Jia X, Cao Y, Gao P, Fu X, Ying K, Chen W, Jiang Y. 2006. Caplp is involved in multiple pathways of oxidative stress response in Candida albicans. Free Radic Biol Med 40: 1201-1209.

Wellington M, Koselny K, Krysan DJ. 2012. Candida albicans morphogenesis is not required for macrophage interleukin $1 \beta$ production. MBio 4: e00433-00412.

Welsh O, Vera-Cabrera L, Rendon A, Gonzalez G, Bonifaz A. 2012. Coccidioidomycosis. Clin Dermatol 30: 573-591.

Wheeler R, Kombe D, Agarwala S, Fink G. 2008. Dynamic, morphotype-specific Candida albicans $\beta$-glucan exposure during infection and drug treatment. PLoS Pathog 4: e1000227.

Whiston E, Wise H, Sharpton T, Jui G, Cole G, Taylor J. 2012. Comparative transcriptomics of the Saprobic and parasitic growth phases in Coccidioides pp. PLoS ONE 7: e41034.

Youseff B, Holbrook E, Smolnycki K, Rappleye C. 2012. Extracellular superoxide dismutase protects histoplasma yeast cells from host-derived oxidative stress. PLoS Pathog 8: e1002713.

Zaragoza O, Nielsen K. 2013. Titan cells in Cryptococcus neoformans: Cells with a giant impact. Curr Opin Microbiol 16: 409-413.

Zaragoza O, Chrisman C, Castelli M, Frases S, Cuenca-Estrella M, Rodriguez-Tudela J, Casadevall A. 2008. Capsule enlargement in Cryptococcus neoformans confers resistance to oxidative stress suggesting a mechanism for intracellular survival. Cell Microbiol 10: 2043-2057.

Zhu X, Gibbons J, García-Rivera J, Casadevall A, Williamson P. 2001. Laccase of Cryptococcus neoformans is a cell wallassociated virulence factor. Infect Immun 69: 5589-5596. 


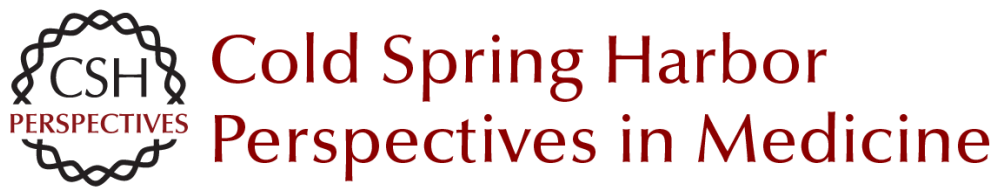

\section{Fungal Pathogens: Survival and Replication within Macrophages}

Andrew S. Gilbert, Robert T. Wheeler and Robin C. May

Cold Spring Harb Perspect Med 2015; doi: 10.1101/cshperspect.a019661 originally published online November 10, 2014

\section{Subject Collection Human Fungal Pathogens}

\section{Evolutionary Perspectives on Human Fungal Pathogens John W. Taylor}

Black Molds and Melanized Yeasts Pathogenic to Humans Anuradha Chowdhary, John Perfect and G. Sybren de Hoog

Fungal Pathogens: Survival and Replication within Macrophages Andrew S. Gilbert, Robert T. Wheeler and Robin C. May

Innate Defense against Fungal Pathogens Rebecca A. Drummond, Sarah L. Gaffen, Amy G. Hise, et al.

Antifungal Pharmacokinetics and Pharmacodynamics Alexander J. Lepak and David R. Andes

Human Fungal Pathogens of Mucorales and Entomophthorales

Leonel Mendoza, Raquel Vilela, Kerstin Voelz, et al.

Functional Profiling of Human Fungal Pathogen Genomes

Alexi I. Goranov and Hiten D. Madhani

Aspergillus fumigatus and Related Species Janyce A. Sugui, Kyung J. Kwon-Chung, Praveen R. Juvvadi, et al.
Thermally Dimorphic Human Fungal Pathogens-Polyphyletic Pathogens with a Convergent

Pathogenicity Trait Anita Sil and Alex Andrianopoulos

Mechanisms of Antifungal Drug Resistance Leah E. Cowen, Dominique Sanglard, Susan J. Howard, et al.

Treatment Principles for Candida and Cryptococcus Laura C. Whitney and Tihana Bicanic

The Human Mycobiome Patrick C. Seed

Treatment Principles for the Management of Mold Infections

Dimitrios P. Kontoyiannis and Russell E. Lewis

Adaptive Immunity to Fungi Akash Verma, Marcel Wüthrich, George Deepe, et al.

The Candida Pathogenic Species Complex Siobhán A. Turner and Geraldine Butler

Fungal Morphogenesis Xiaorong Lin, J. Andrew Alspaugh, Haoping Liu, et al.

For additional articles in this collection, see http://perspectivesinmedicine.cshlp.org/cgi/collection/ 